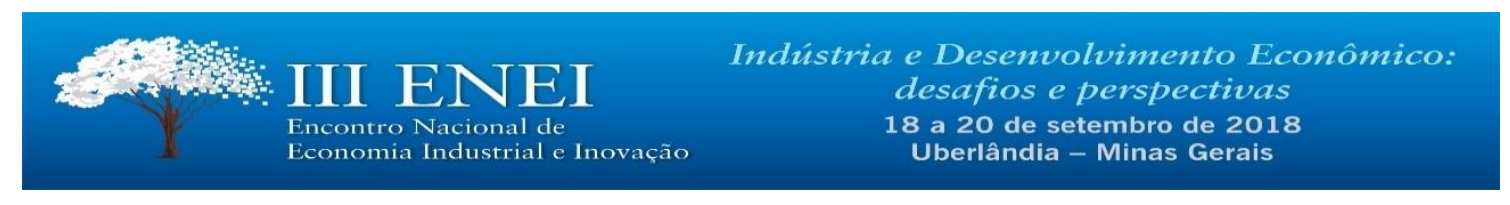

\title{
DESENVOLVIMENTO ORIENTADO À INOVAÇÃO: A ESTRATÉGIA DA CHINA PARA EVITAR A ARMADILHA DA RENDA MÉDIA
}

\author{
Ricardo Muniz Muccillo da Silva ${ }^{1}$ \\ André Moreira Cunha ${ }^{2}$
}

\section{RESUMO}

O mundo volta suas atenções para o fenômeno de crescimento econômico observado na China nas últimas décadas. A literatura contemporânea destaca as iniciativas do governo chinês para transformar o país em uma potência voltada para a geração de inovações tecnológicas. Dentro desse contexto, sugere-se que existe um projeto estratégico, idealizado e organizado pelo Estado chinês, para promover a capacidade endógena de gerar inovações tecnológicas como um dos meios para a resolução dos principais entraves ao crescimento do país, tais como: a manutenção da alta produtividade; a diminuição da deterioração na distribuição de renda; a redução dos impactos do crescimento em termos de poluição ambiental; a criação de fontes de energia sustentáveis e renováveis, das quais o país possui enorme carência; aproximação do país da fronteira tecnológica global. Para além disso, conforme destacado na literatura, o desenvolvimento da capacidade de gerar inovações e superar os obstáculos supramencionado, seria é fundamental para garantir o crescimento sustentável da renda e evitar a armadilha da renda média, facilitando a transição do país do status de renda média para a alta. Diante do exposto, essa pesquisa busca explorar as questões referentes a hipótese de a China estar enfrentando um período de crescimento econômico mais baixo, e, por consequência, cair na armadilha da renda média.

Palavra-chave: Políticas de Ciência, Tecnologia e Inovação; Armadilha da renda média; Desenvolvimento tecnológico da China.

\section{ABSTRACT}

The world turns its attention to the phenomenon of economic growth observed in China in recent decades. Contemporary literature highlights the initiatives of the Chinese government to transform the country into a power for the generation of technological innovations. Within this context, it is suggested that there is a strategic project, idealized and organized by the Chinese State, to promote the endogenous capacity to generate technological innovations as one of the means to solve the main obstacles to the growth of the country, such as: high productivity; the decrease in the deterioration in the distribution of income; reducing the impacts of growth in terms of environmental pollution; the creation of sustainable and renewable energy sources, of which the country has an enormous shortage; the country's technological frontier. Moreover, as highlighted in the literature, the development of the capacity to generate innovations and overcome the above obstacles would be essential to ensure sustainable income growth and avoid the middle income trap, facilitating the transition of the country from the middle income status to the high. In the light of the foregoing, this research seeks to explore the questions regarding the hypothesis that China is experiencing a period of lower economic growth and, consequently, fall into the middle income trap.

Key words: Science, Technology and Innovation Policies; Middle-Income Trap; China's technological development.

Área 6: Políticas públicas e regulação - 6.2 Políticas de Ciência, Tecnologia e Inovação. JEL: 03

1 Doutor pelo Programa de Pós-Graduação em Economia da UFRGS. E-mail: ricardomusi@hotmail.com

2 Professor do Programa de Pós-Graduação em Economia da UFRGS e Pesquisador do CNPq. E-mail: andre.cunha@ufrgs.br 


\section{INTRODUÇÃO}

A ascensão da China à condição de potência global desponta como um dos casos mais extraordinários de mudança estrutural observados na história, especialmente devido à velocidade de sua transformação e do seu grau de intensidade. Alguns estudos recentes ${ }^{3}$ destacam que a evolução tecnológica da China, registrada nas últimas três décadas, faz parte de um plano estratégico do governo chinês para consolidar o país como potência capaz de gerar conhecimento. Esses estudos ainda mencionam o grande esforço estatal para aprofundar, cada vez mais, essa metamorfose estrutural e induzir à inovação nativa na China, como um meio de diminuir a dependência tecnológica do país. O desenvolvimento de sua capacidade de inovação seria a condição necessária para o crescimento sustentável e para evitar a armadilha da renda média (middle-income trap), facilitando a transição do país do status de renda média para alta. Desse modo, as inovações tecnológicas teriam um caráter de urgência na superação de inúmeros problemas estruturais chineses que poderão interferir no crescimento do país no médio e no longo prazo, entre os quais: o desafio da manutenção da alta produtividade; mitigar a deterioração na distribuição de renda; garantir eficiência no uso dos recursos naturais; diminuir os impactos do crescimento em termos de poluição ambiental; criar fontes de energia sustentáveis e renováveis, das quais o país possui enorme carência. Nesse sentido, alguns estudos $^{4}$ destacam a hipótese de que os problemas supramencionados, estariam interferindo na recente desaceleração do crescimento econômico da China observado nos últimos anos ${ }^{5}$. Realizadas as considerações introdutórias, alguns questionamentos são pertinentes como ponto inicial de reflexão desse estudo: o processo de desaceleração do crescimento econômico da China observado nos últimos anos, sugere que o país está entrando na armadilha da renda média? Conforme literatura pesquisada, os programas voltados para o desenvolvimento da ciência, da tecnologia e da inovação na China, sugerem a intencionalidade do Estado em criar as condições institucionais necessárias para evitar a armadilha da renda média?

O presente artigo tem como objetivo compreender e analisar as evidências empíricas encontradas na literatura, que sugerem a hipótese de que a recente desaceleração do crescimento econômico da China, seria um forte indicativo de que o país está entrando na armadilha da renda média. Esse fenômeno é comum entre os países emergentes que não conseguiram desenvolver a capacidade de gerar inovações tecnológicas nativas e transitaram de forma rápida do status de renda baixa para média. Para além disso, ciente desta possibilidade, presume-se que o Estado da China estaria lançando, de forma sistemática, programas de desenvolvimento de ciência, tecnologia e inovação, como vetores para mitigar a situação supramencionada. O êxito das políticas tecnológicas promovidas pelo Estado chinês seria capaz de restaurar o papel de potência geradora de conhecimento da China, no mundo, como o havia sido até o século XVIII. O desenvolvimento tecnológico do país poderia ser capaz de evitar a armadilha da renda média, permitindo a transição do país do status de renda média para a alta.

A principal hipótese de pesquisa é a de que, os inúmeros programas de promoção das inovações tecnológicas na China, são uma resposta do Estado chinês para evitar a armadilha da renda média e consolidar o país como potência global hegemônica. Sugere-se a existência de uma consciência do governo chinês de que o modelo de exportação de produtos montados com componentes importados de outras economias não seria mais suficiente para atender às necessidades chinesas; e que estaria perto do esgotamento o modelo de crescimento baseado em ganhos de produtividade com a incorporação de mão de obra das áreas rurais do país e a importação de tecnologia de países mais avançados. Daí deriva o caráter evolucionário das transformações

${ }^{3}$ Ver: IEDI (2011); World Bank (2013); Wang (2013); Mazzucato (2013); Someren; Someren-wang (2013); Medeiros (2013); Ping (2013); Bingwen (2013); Dongqi (2013); Guangsi (2013); Zhaoxia (2013); Cheung (2014); Hu (2014); Fu (2015); Liu (2015) ; Ding;Li, (2015); Johnson (2015); Tselichtchev (2015); OECD (2016); WIPO (2016); WEF (2016); e IMF (2016).

4 Lewis (1954); Eichengreen (2012); Lin; Treichel (2012); Agenor, Canuto; Jelenic (2012); Eichengreen; Park; Shin (2013); Bingwen (2013); OECD (2013); Dongqi (2013); Guangsi (2013); Agenor; Canuto (2014); IMF (2014); Fu (2015); Liu (2015); Ding; Li (2015); Gill; Kharas (2015); OECD (2016a), UNCTAD (2016b).

${ }^{5}$ A economia da China cresceu 6,7 por cento no ano de 2017, o ritmo mais lento em 26 anos (SILVA, 2017 p.73). 
institucionais do país em prol das inovações desenvolvidas em território nacional em resposta às mudanças estruturais ocorridas nas últimas décadas. Como fonte de inspiração metodológica para o estudo proposto, adota-se o modelo de análise de intencionalidade do Estado utilizado por Weber (2012), que possui como base a perspectiva de "ação social racional com relação a fins".

Realizadas as considerações introdutórias necessárias, a estrutura do estudo é a seguinte: inicialmente, apresenta-se a delimitação do tema e a principal hipótese de pesquisa; em sequência, realiza-se a exposição sobre o conceito de armadilha da renda média; a seguir, apresenta-se uma breve evolução dos indicadores de inovação tecnológica na China, e uma análise das possíveis evidências da armadilha da renda média no país estudado. Na parte final apresenta-se a conclusão do estudo, encerrando-se com as principais referências adotadas para a elaboração deste artigo.

\section{ARMADILHA DA RENDA MÉDIA}

Os exemplos históricos revelam que muitas economias podem atingir o status de renda média em curto espaço de tempo. Não obstante, poucas conseguem ultrapassar a barreira da renda média. Isso ocorre porque as mudanças políticas e institucionais necessárias para atingir níveis de renda mais elevados são muito mais complexas e mais impactantes em termos tecnológicos, políticos e sociais (AGENOR; CANUTO; JELENIC, 2012; BINGWEN, 2013; OECD, 2013; UNESCO, 2015; EICHENGREEN; PARK; SHIN, 2013). Alguns estudos destacam que menos de um quarto das economias que atingiram os níveis de renda média conseguiram ultrapassar o patamar de renda média para a alta nas últimas décadas ${ }^{6}$. Os fatores que diferenciam os países que fizeram a transição dos demais estão, em grande parte, ligados à qualidade das políticas econômicas e sociais implementadas pelo Estado. Além disso, esses países tiveram como característica a manutenção dos ganhos de produtividade relacionados à qualificação da mão de obra e a melhoria das condições tecnológicas internas. No caso específico do Leste Asiático, as economias que puderam transitar do nível de renda média para a alta (Japão, Coreia do Sul, Taiwan, Singapura e Hong Kong) conseguiram desenvolver a capacidade de gerar inovações, diminuindo a dependência das tecnologias externas:

As economias asiáticas que foram capazes de transitar do status de renda
média para alta, desenvolveram suas capacidades internas de gerar
inovações tecnológicas e de aproximação com a fronteira tecnológica.
Estes países passaram de imitadores e importadores de tecnologias para
nações capazes de gerar inovações nativas. As fortes proteções dos direitos
de propriedade intelectual têm sido um fator importante no fomento destas
inovações nativas (AGENOR; CANUTO; JELENIC, 2012 p.5, tradução
nossa).

Nesse sentido, sugere-se que a capacidade de gerar inovações é fundamental para que a China evite a "armadilha da renda média". Para Agenor, Canuto, e Jelenic (2012), os ganhos obtidos por países asiáticos referentes à mão de obra barata e os ganhos decorrentes da imitação de tecnologias estão caminhando para o esgotamento. No passado recente, os países em desenvolvimento, principalmente os do leste asiático, usando uma combinação de tecnologias importadas, adaptação criativa e mão de obra barata, obtiveram ganhos extraordinários de produtividade. Nesse período de evolução, os trabalhadores se deslocaram entre os setores da economia de baixa produtividade, geralmente ligados a atividades agrícolas, para os setores industriais (LEWIS, 1954; AGENOR; CANUTO; JELENIC, 2012; EICHENGREEN, 2012; EICHENGREEN; PARK; SHIN, 2013; OECD, 2013). Esse movimento foi observado com bastante intensidade na China nas décadas de 1990 até o fim dos anos 2000, e, segundo o World Bank (2013), quase 500 milhões de chineses se deslocaram das zonas agrícolas para as zonas urbanas e industriais da costa leste do país.

6 “Estimasse que de 101 economias de renda média em 1960, apenas 13 tornaram-se economias de renda alta até 2008 - Guiné Equatorial, Grécia, Hong Kong (China), Irlanda, Israel, Japão, Maurício, Portugal, Porto Rico, República da Coreia, Singapura, Espanha e Taiwan” (AGENOR; CANUTO; JELENIC, 2012 p.1, tradução nossa). 
À medida que os países em desenvolvimento atingem os níveis de renda média, os salários urbanos sobem e os ganhos de produtividade com a importação de tecnologias começam a declinar. No caso da China, atualmente os salários médios pagos pela indústria já superam os valores de diversos países emergentes. Para fins de comparação, o salário médio pago pela indústria chinesa triplicou entre 2005 e 2016, passando, respectivamente, de U\$ 1,20 por hora (2005) para U\$ 3,60 por hora $(2016)^{7}$. Esse movimento também ocorreu em outros segmentos da economia chinesa, e os trabalhadores da China já possuem rendimentos médios maiores que os trabalhadores da Argentina, do Brasil e do México. Além disso, em 2016 o salário médio dos trabalhadores chineses já está perto de superar alguns países da Europa Ocidental - Portugal e Grécia. A melhoria da produtividade total dos fatores e a incorporação de mão de obra mais qualificada no mercado de trabalho foram determinantes para a trajetória ascendente dos rendimentos dos trabalhadores chineses.

Para Agenor; Canuto; Jelenic (2012), o crescimento da produtividade via realocação setorial e os ganhos de produtividade com a importação de tecnologias se esgotam, em consequência, o crescimento econômico desacelera. Nesse momento, a economia do país pode estagnar, permanecendo na "armadilha da renda média", que representa a incapacidade de transitar da renda média para a alta. Nesse cenário, os países de renda média têm dificuldade de competir com os países de renda mais baixa que fabricam produtos de menor valor agregado e com os países de renda alta que produzem bens e serviços mais sofisticados.

Para evitar tal situação os governos podem agir, antecipadamente, da seguinte forma: investimentos em educação e qualificação da população; infraestrutura avançada; priorizar os setores intensivos em conhecimento e com maior sofisticação tecnológica; estabelecer leis de direito de propriedade; financiamento de atividades inovadoras; e criar políticas para acumulação e difusão do conhecimento (AGENOR; CANUTO; JELENIC, 2012). Na mesma linha de pensamento, para UNCTAD (2016b), os estudos recentes destacam que a pouca sofisticação tecnológica dos produtos exportados, além da baixa diversidade de produtos exportados, tem sido associada à armadilha de renda média. Nesse caso, países que atingiram o nível de renda média, mas possuem pautas reduzidas de exportação e com pouca sofisticação tecnológica, estão mais vulneráveis a cair na armadilha da renda média.

Para os padrões do Banco Mundial ${ }^{8}$, a China já é considerada uma economia de renda média alta, e está entrando em uma fase potencialmente "perigosa" do seu desenvolvimento. Para Eichengreen (2012) e Gill; Kharas (2015), a China vive um momento de transição da política de subvalorizarão da taxa de câmbio, a qual foi um dos alicerces do crescimento das exportações de produtos com pouca sofisticação tecnológica e da proteção das empresas estatais vinculadas ao setor de exportação - Commodities. A filosofia que prevaleceu até o começo dos anos 2000 , de câmbio desvalorizado e foco nas exportações de produtos intensivos em mão de obra, poderia retardar a migração da produção para a produção de produtos de maior sofisticação tecnológica. Ainda segundo Eichengreen (2012), ao examinar a evolução do crescimento de inúmeros países de renda média, nota-se que os países que obtiveram um rápido crescimento, começaram a desacelerar quando atingiram cerca de US\$16.000 do PIB per capita ${ }^{9}$.

Em outro estudo realizado mais recentemente, os dados foram corrigidos para a existência de dois modos como marcos da desaceleração, um em torno de US \$ 15.000 e outro em torno de US \$ 11.000 (EICHENGREEN; PARK; SHIN, 2013). Na Figura 1 é possível visualizar o crescimento da renda per capita na China e o coeficiente de Gini, utilizado para medir a desigualdade de distribuição de renda. Constata-se que, embora a renda per capita do país tenha crescido de forma considerável

\footnotetext{
${ }^{7}$ Fonte: http://www.euromonitor.com/china

8 (https://datahelpdesk.worldbank.org/knowledgebase/articles/906519).

9 "Achamos que as desacelerações do crescimento geralmente ocorrem em renda per capita de US \$16.700.4. Nesse ponto, a taxa de crescimento per capita diminui de $5,6 \%$ para $2,1 \%$ ou em média 3,5 pontos percentuais. Para fins de comparação, note-se que o PIB per capita da China, em preços internacionais constantes (preço de paridade de compra), foi de US \$ 8.500 em 2007. Extrapolando sua taxa de crescimento entre então e agora, a China atingirá o valor limiar de US \$ 15.100 em torno de 2016, isto é para dizer, cinco anos depois ” (EICHENGREEN, 2012 p. 410, tradução nossa).
} 
nas últimas décadas, a sua distribuição não evoluiu no mesmo ritmo. Tal situação revela que o crescimento da renda ficou, majoritariamente, concentrado em algumas regiões e camadas da sociedade chinesa.

Figura 1: Coeficiente de GINI e PIB nominal per capita 1980 - 2021 (US\$)

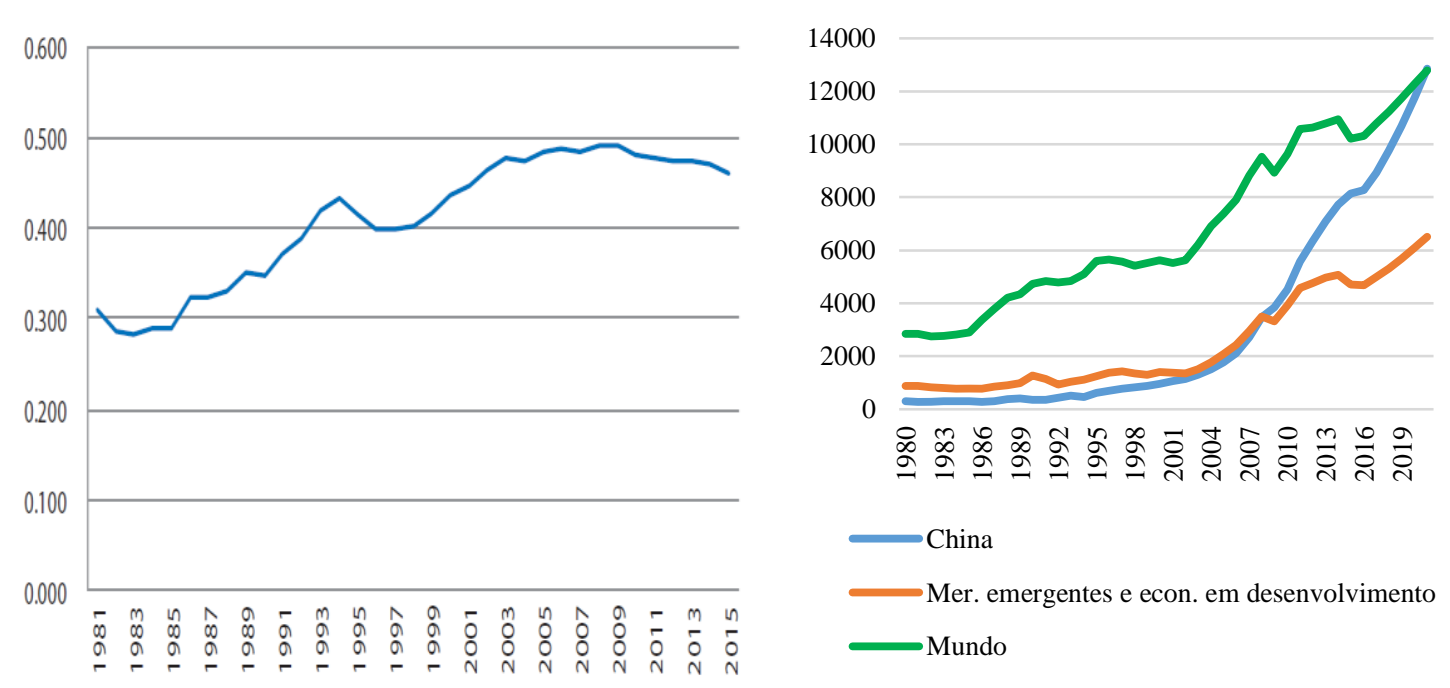

Fonte: elaborado pelo autor com base nos dados do $\operatorname{IMF}^{10}(2017)$.

Assim, para evitar a armadilha da renda média, a China deverá desenvolver a capacidade de gerar inovações nativas. Segundo alguns estudos relacionados, a desaceleração do crescimento das economias que atingiram o nível de renda média é menos provável em países que apresentaram: melhoria dos níveis educacionais; quando produtos de alta tecnologia representam uma grande parcela das exportações totais do país; aumento do grau de sofisticação e diversificação da produção do país; acesso a financiamentos para inovação; e melhoria dos indicadores internos de inovação (EICHENGREEN, 2012; LIN; TREICHEL, 2012; AGENOR; CANUTO; JELENIC, 2012; EICHENGREEN; PARK; SHIN, 2013; BINGWEN, 2013; OECD, 2013; DONGQI, 2013; GUANGSI, 2013; AGENOR; CANUTO, 2014; IMF, 2014; UNESCO, 2015; FU, 2015; LIU, 2015; DING; LI, 2015; GILL; KHARAS, 2015; OECD, 2016a, UNCTAD, 2016b).

Outro grande desafio que deve ser superado para o desenvolvimento social da China é a questão do envelhecimento da população. A China está "envelhecendo antes de enriquecer." Segundo o World Bank (2015), o pico da disponibilidade da força de trabalho na China será atingido entre os anos de 2015 e 2016. A partir desse momento o envelhecimento da população passa a ser cada vez maior. Segundo os dados da UNESCO, apresentados no Na Figura 2, a diminuição da força de trabalho deverá ocorrer perto dos anos de 2020 e 2025. O evento preocupa os governantes do país porque a abundância da força de trabalho e juventude de grande parte da população foi um dos grandes diferenciais competitivos da China nas últimas décadas.

${ }^{10} \mathrm{O}$ produto interno bruto é a medida única mais utilizada da atividade econômica geral de um país. Representa o valor total a preços atuais dos bens e serviços finais produzidos em um país durante um período de tempo especificado dividido pela população média pelo mesmo ano.

(http://www.imf.org/external/datamapper/NGDPDPC@WEO/OEMDC/WEOWORLD/CHN). 

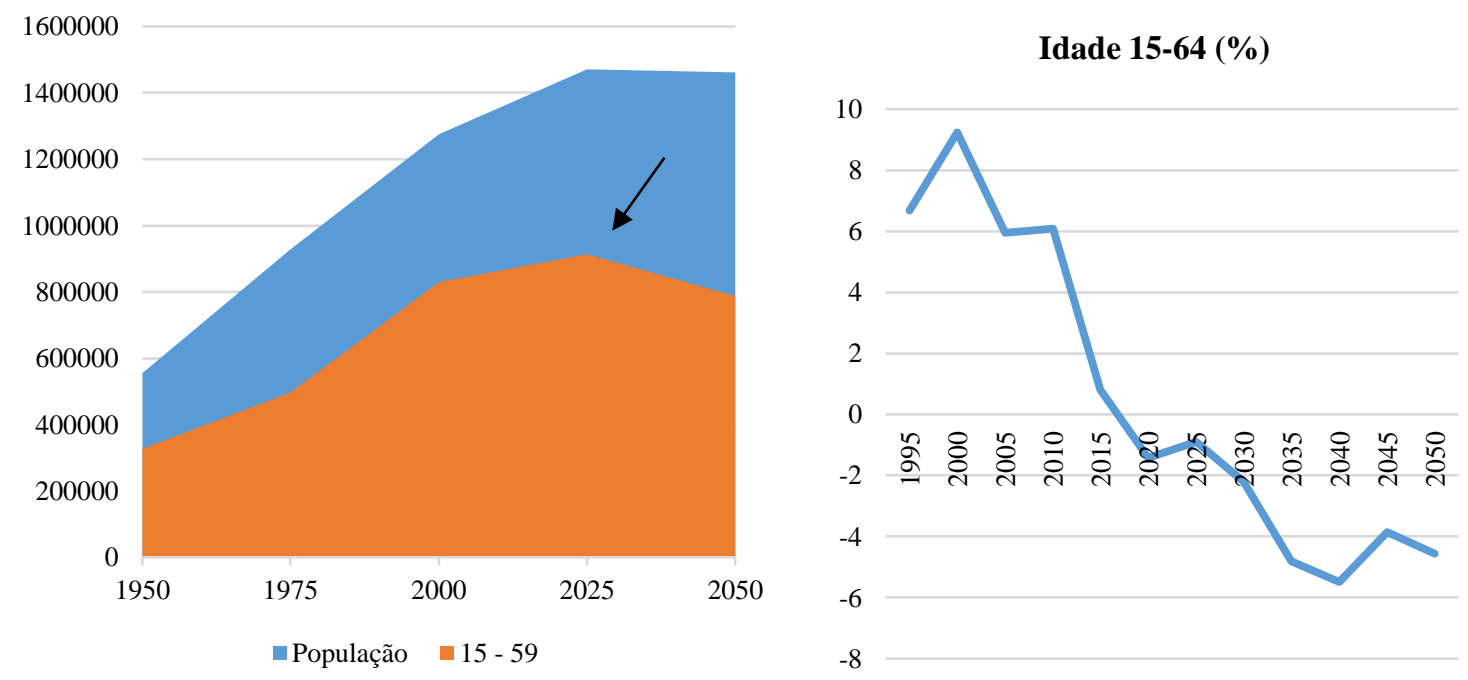

Fonte: elaborado pelo autor com base nos dados da UNESCO ${ }^{11}$; IMF (2016 p.90)

Embora ainda não se tenha um consenso absoluto sobre a data específica do ponto de inflexão do crescimento da força de trabalho na China, é fato que o evento está perto de ocorrer. A diminuição da disponibilidade da força de trabalho e o envelhecimento da população é um fator que acelera a necessidade do desenvolvimento tecnológico do país e do aumento da produtividade do trabalho. Essa situação coloca uma carga extra de exigências sobre o sistema de educação e de formação de novos trabalhadores. Será necessário formar indivíduos mais qualificados e eficientes para suportar a diminuição da força de trabalho, o envelhecimento da população e as mudanças estruturais de produção que devem ocorrer nas próximas décadas. Além disso, a escassez de recursos naturais é mais um elemento que coloca pressão extra sobre a gestão dos fatores de produção na China. Será necessário produzir mais com menos insumos, ou seja, uma produção mais sustentável e eficiente.

\section{O PROGRESSO DOS INDICADORES DE INOVAÇÃO NA CHINA}

Conforme abordado anteriormente a capacidade de gerar inovações tecnológicas é fundamental para transição do país do status de renda média para alta. Dentro dessa perspectiva, a análise dos indicadores de inovação fornece os subsídios necessários para a constatação de que as políticas empregadas pelo Estado, na intenção de promover o desenvolvimento tecnológico na China, tiveram, supostamente, alguma efetividade. Nesse sentido, define-se transição ${ }^{12}$ como sendo um conjunto de alterações institucionais (normas, convenções, hábitos, cultura, crenças, regras formais e informais) relacionadas à capacidade dos agentes do país de se apropriarem, difundir e criar novos conhecimentos que possam representar criação de inovações. A mudança institucional é algo que ocorre de forma lenta e depende da combinação de fatores coletivos e individuais, pois envolve a mediação entre os mercados, as ações do Estado, os interesses coletivos e os interesses individuais (METCALFE, 2001; HODGSON, 2006; CHANG, 2008). Examinando-se as ações realizadas é possível verificar a intencionalidade do Estado em promover a transformação do país de forma consciente e planejada.

Desde a abertura, em 1978, a questão da inovação na China é tratada como um assunto de extrema importância para o país. A ciência e a tecnologia ganharam o status de principal força produtiva, e a forte atuação do Estado na economia reflete a melhoria induzida das condições de

\footnotetext{
${ }^{11} \mathrm{http} / / /$ www.un.org/esa/population/publications/worldageing19502050/pdf/065china.pdf
}

${ }^{12}$ Conforme: Metcalfe (2001); Perez (2004); Chang (2008); Freeman; Soete (2008). 
infraestrutura tecnológica. No entanto, é importante ressaltar que o avanço tecnológico chinês, nas últimas décadas, é consequência da convergência de ações dos setores público e privado. A melhoria da capacidade tecnológica das empresas chinesas não ocorreu somente com o aumento significativo nos investimentos em P\&D interno constatado nos dados investigados, mas com o desenvolvimento dos sistemas de inovação, os quais permitiram maior difusão e maior aprimoramento das tecnologias produzidas no país.

Sobre os indicadores de inovação, de acordo com um ranking de 40 países produzido pela Academia Chinesa de Ciência e Tecnologia para o Desenvolvimento, a China está em $21^{\circ}$ lugar em capacidade inovadora. Nesse ranking, o país atingiu a marca de 58 pontos, ao passo que os Estados Unidos possuem 100 pontos (WORLD BANK, 2013 p. 166). Ainda segundo a Academia Chinesa de Ciência e Tecnologia para o Desenvolvimento, o índice foi construído a partir de cinco categorias principais, com base em 31 indicadores de inovação. A diferença de pontuação entre China e Estados Unidos materializa o grande hiato que existe entre os países. O mesmo relatório também destaca que desde 2000 a China tem melhorado o seu desempenho na criação de conhecimento.

Em outro estudo importante realizado sobre indicadores mundiais de inovação, o The Global Innovation Index 2016 (WIPO, 2016), relata que a China ingressou no grupo das 25 economias mais inovadoras do mundo no ano de 2015. A classificação é realizada com base no desempenho de 82 indicadores de inovação e seus impactos na economia. No mesmo relatório desenvolvido em 2013 The Global Innovation Index 2013, a China ocupava a 35 lugar no ranking de inovação. O estudo ainda revela que no segmento de países de renda média ${ }^{13}$, a China é considerada a nação que possui as melhores condições de gerar inovações do mundo. Essas informações sintetizam os avanços registrados nos indicadores de inovação da China nos últimos anos.

De acordo com estudo recente publicado pela OECD (2016a), a China tem alcançado resultados expressivos referentes à capacidade de gerar inovações. Após três décadas de alta taxa de crescimento econômico sem precedentes, para continuar a trajetória de crescimento sustentável os governantes da China estão engajados na promoção da Ciência, Tecnologia e Inovação (C, T\&I) como motores essenciais para o crescimento do país. Atualmente, a China é o segundo país que mais investiu em P\&D no mundo, ficando apenas atrás dos Estados Unidos. O $13^{\circ}$ Plano Quinquenal, lançado em 2016, estabeleceu um novo conjunto de metas e políticas públicas para o desenvolvimento de C, T\&I. Essas novas estratégias corrigem e atualizam as trajetórias determinadas no Programa MLP (2006/2020) e nos Planos Quinquenais anteriores. Na última década, o governo chinês constatou a necessidade de maior vitalidade e engajamento da participação empresarial na geração de inovações tecnológicas. Assim, buscando estimular a iniciativa empresarial, o governo lançou, em 2015, a estratégia nacional para o empreendedorismo em massa e inovação. Portanto, a ação do Estado busca encorajar o empreendedorismo no país.

Em outro relatório desenvolvido pelo World Economic Forum (2016), a China ocupa a 59a posição em um ranking que combina diversos fatores: ambiente político e regulatório; ambiente de negócios e inovação em infraestrutura; acessibilidade; políticas públicas; esforço empresarial; impactos econômicos das inovações; e impactos sociais das inovações. Semelhante ao que é destacado no relatório da OECD (2006a), o estudo elaborado pelo World Economic Forum (2016) também aborda a necessidade da melhoria das condições do setor empresarial do país.

Para Baller; Dutta; Lanvin (2016), as empresas chinesas precisarão intensificar seus esforços para adotar as tecnologias digitais e estimular processos inovadores. Embora tenha ocorrido considerável aumento do registro de patentes por parte das empresas chinesas nos últimos anos, esse aumento ainda é relativamente baixo em comparação ao das economias avançadas. O setor empresarial do país continua a ser um dos principais pontos de estrangulamento na capacidade do

13 "Para o atual ano fiscal de 2017, as economias de baixa renda são definidas como aquelas com RNB per capita, calculadas usando o método do Atlas do Banco Mundial, de US \$ 1.025 ou menos em 2015; as economias de baixa renda média são aquelas com RNB per capita entre US \$1.026 e US \$ 4.035; as economias de renda média superior são aquelas com RNB per capita entre US \$ 4.036 e US \$ 12.475; as economias de alta renda são aquelas com RNB per capita de US \$ 12.476 ou mais" (https://datahelpdesk.worldbank.org/knowledgebase/articles/906519, tradução nossa). 
país de gerar inovações. Segundo o relatório World Economic Forum, no item ambiente de negócios e inovação a China ocupa a $104^{\mathrm{a}}$ posição no mundo, resultado que a coloca muito abaixo de outros importantes países asiáticos. Esse relatório atribui essa dificuldade ao fato de a China manter impostos elevados sobre as empresas e processos longos e complexos para criação de novos negócios. Reconhecendo esse desafio, o Estado chinês está engajado em simplificar o processo de abertura de novos negócios, através da estratégia nacional para o empreendedorismo. Um ponto positivo destacado no relatório do World Economic Forum são os impactos econômicos e sociais das inovações na China, em cujos itens, respectivamente, o país ocupa as $37^{\mathrm{a}}$ e $41^{\mathrm{a}}$ posições. Outro fator de destaque referido são as políticas públicas de inovação, em que o país ocupa a $40^{a}$ posição, acima da média geral dos países de renda média.

Quando se trata de produtividade dos países, o Índice de Competitividade (GCI), publicado pelo Fórum Econômico Mundial (WEF, 2016), tem como objetivo definir indicadores que revelem o grau de produtividade e desenvolvimento que um país possa atingir. O relatório define competitividade como "o conjunto de instituições, políticas e fatores que determinam o nível de produtividade de uma economia, o que, por sua vez, de prosperidade que o país pode alcançar" (WEF, 2016 p. 5, tradução nossa). O GCI combina 114 indicadores que incorporam conceitos que determinam o grau de competitividade e prosperidade de um país, agrupados em 12 pilares: instituições, infraestrutura, ambiente macroeconômico, saúde e educação primária, ensino superior e capacidade de treinamento, eficiência de mercado, eficiência do mercado de trabalho, desenvolvimento do mercado financeiro, disponibilidade tecnológica, tamanho do mercado, sofisticação do ambiente de negócios e inovações. Os pilares mencionados são, por sua vez, agrupados e organizados em três subgrupos: a) requisitos básicos; b) intensificadores de eficiência; c) inovação e sofisticação.

Para fins metodológicos de cálculo do GCI são levados em consideração o tamanho do PIB per capita dos países e a participação de recursos naturais no total das exportações. Essa medida foi justificada pelo Fórum Econômico Mundial porque o boom das commodities produzidos pelo superciclo distorceu os dados de competitividade de alguns países em relatórios anteriores. Para cálculo do GCI, ainda são considerados os dados estatísticos obtidos com reconhecidos organismos internacionais ${ }^{14}$.

Esses indicadores produzidos pelo WEF (2016), no relatório de competividade global, revelam que a China tem apresentado, nas últimas décadas, melhora gradativa no nível de competitividade e prosperidade. No estudo produzido no ano de 2016 , a China ocupava o $28^{\circ}$ lugar no ranking global de competitividade. Para fins de comparação, no mesmo relatório produzido no ano de 2006, o país ocupava o $54^{\circ}$ lugar. Segundo WEF (2016), a China apresentou um progresso considerável em áreas importantes: sofisticação dos negócios e melhoria dos indicadores de educação. É importante destacar que todos os relatórios e estudos pesquisados para a produção do presente estudo são unânimes em afirmar que existe significativa melhoria em diversos indicadores de educação na China (IEDI 2011; GUANGSI, 2013; WORLD BANK, 2013; UNESCO, 2013; FU, 2015; DING; LI, 2015; UNESCO, 2015; OECD, 2016a; OECD, 2016b; WTO, 2016; BALLER; DUTTA; LANVIN, 2016; WIPO, 2016, UNCTAD, 2016, WEF, 2016; IMF, 2016).

O relatório do WEF (2016) ainda destaca que dentro dos três estágios de competitividade desatacados (requisitos básicos; intensificadores de eficiência; e inovação e sofisticação) a China encontra-se no segundo estágio. Os países que estão nesse grupo possuem eficiência significativa no aprimoramento das tecnologias existentes, índices de educação satisfatórios e um mercado de trabalho consolidado em diversos ramos que exigem baixa ou média qualificação. Para que o país possa avançar para o estágio 3 (inovação e sofisticação), é necessário desenvolver a capacidade de gerar inovações nativas e a qualificação da mão de obra. Tais medidas são fundamentais para que o país consiga atingir níveis elevados de competição na cadeia internacional de valor e que a renda dos

14 “O GCI inclui dados estatísticos de organizações internacionalmente reconhecidas, nomeadamente o Fundo Monetário Internacional (FMI); o Banco Mundial; e várias agências especializadas das Nações Unidas, incluindo a União Internacional das Telecomunicações, a UNESCO e a Organização Mundial da Saúde”. (WEF, 2016 p. 4, tradução nossa). 
trabalhadores continue a aumentar de forma sustentável, evitando a armadilha da renda média (AGENOR; CANUTO; JELENIC, 2012; EICHENGREEN; PARK; SHIN, 2013; OECD, 2016).

Existe, ainda, convergência de outros estudos realizados pelo Banco Mundial, IEDI, IPEA, OCDE, WEF, WTO, The Global Innovation Index e da Academia Chinesa de Ciência e Tecnologia para o Desenvolvimento (CRUZ, 2011; GUANGSI, 2013;WORLD BANK, 2009 e 2013; IEDI 2011a; UNESCO, 2013; UNESCO, 2015; FU, 2015; DING; LI; OECD, 2016a; WTO, 2016; BALLER; DUTTA; LANVIN, 2016; WIPO, 2016, UNCTAD, 2016, WEF, 2016) os quais, em linhas gerais, confirmam a hipótese de que a China avançou significativamente na capacidade de gerar inovações tecnológicas. Não obstante, é importante destacar que todos os estudos mencionados ressaltam que ainda existem enormes diferenças entre os indicadores de inovação apresentados pela China e os indicadores de países mais desenvolvidos.

Outro ponto importante destacado pelo relatório The Global Innovation Index 2016 foi a melhoria significativa nas condições educacionais e de pesquisa científica do país. A questão do ensino e da aprendizagem é tratada como uma das prioridades do Estado chinês para o desenvolvimento da capacidade de gerar inovações nativas. Nesse sentido, o governo realizou amplas reformas no sistema educacional nas décadas de 1980 e 1990 em todos os níveis, com o objetivo de facilitar o acesso e melhorar as condições de ensino no país. As metas estabelecidas nos últimos Planos Quinquenais e nos programas de C\&T demandam a formação de pessoal qualificado em áreas consideradas estratégicas. A formação de novos cientistas e pesquisadores é um dos objetivos estabelecidos para facilitar a criação e a difusão de novos conhecimentos. Para atingir essa meta, uma das medidas estabelecidas foi o estabelecimento de novas oportunidades de ingresso de estudantes chineses no ensino superior e a mudança de rumo dos objetivos das instituições de ensino superior na China. No período antes das reformas, as intuições de ensino superior estavam afastadas das necessidades do mercado e não possuíam grandes incentivos para o desenvolvimento de pesquisa, considerando-se que a maior preocupação das instituições de ensino superior era com a formação de mão de obra para atividades mais operacionais (UNESCO, 2015; HIGGINS, 2015; OECD, 2016b). A trajetória iniciada com as reformas de 1978 modificou o papel das instituições de ensino superior que passaram a ser consideradas agentes fundamentais na produção de pesquisa cientifica do país. A partir desse período, as lideranças governamentais chinesas visualizaram, no fomento da ciência e da tecnologia, o alicerce para efetivar as quatro modernizações propostas pelo Estado. Para atender as expectativas geradas pela transformação do país foi necessário formar indivíduos capazes de produzir conhecimento técnico e científico útil, no sentido de contribuir para o processo de modernização da China (WORLD BANK, 2013; HIGGINS, 2015; OECD, 2016a).

\section{DIVERSIFICAÇÃO DAS EXPORTAÇÕES DE ALTA TECNOLOGIA}

Para o IMF (2014), as exportações de bens mais sofisticados, em termos tecnológicos, possuem um impacto importante na menor volatilidade do produto e mais estabilidade macroeconômica. Conforme mencionado anteriormente, em alguns estudos ${ }^{15}$ a sofisticação e a diversificação da pauta de exportações estão sendo correlacionadas como um dos fatores importantes para que os países atinjam o nível de renda alta, evitando a armadilha da renda média.

Em relação ao saldo comercial de produtos de alta tecnologia (Figura 3), constata-se que a China passou por um processo de inversão de déficit na comparação entre importações e exportações de produtos de alta tecnologia, o que revela que a China está modificando o seu perfil de exportação. O primeiro registro de superávit ocorreu no ano de 2004. Cabe salientar que no ano de 2001 e em 2006 ocorreram dois eventos importantes para o fluxo comercial de produtos de alta tecnologia. Em 2001, a China aderiu à OMC, dando um passo importante no processo de internacionalização do país.

${ }^{15}$ Eichengreen; Lin; Treichel, (2012); Agenor; Canuto; Jelenic (2012); Eichengreen; Park; Shin, (2013); Bingwen (2013); OECD, (2013); Dongqi (2013); Guangsi (2013); Agenor; Canuto (2014); IMF (2014); Liu (2015); Ding; Li (2015); Gill; Kharas (2015); OECD (2016a); UNCTAD (2016b). 
Esse evento aumentou significativamente o fluxo de comércio entre a China e os outros países do mundo em todas as áreas. O ingresso do país como membro da OMC pode explicar, pelo menos em parte, o avanço do fluxo comercial de produtos de alta tecnologia que ocorreu a partir desse período. É importante ressaltar que esse fenômeno não foi observado somente no segmento industrial mencionado. A competividade das exportações da China está baseada no conceito de produção de baixo custo, envolvendo a operações de processamento e montagem (PING, 2013; ZHAOXIA, 2013; WORLD BANK; FU, 2015; LUOLIN, 2015).

Por sua vez, a maior transparência das instituições chinesas serviu de forte incentivo para o aumento do volume de investimento direto estrangeiro que passou a ingressar na China. A intensificação do processo de internacionalização das empresas chinesas expôs as empresas do país a um grau de concorrência internacional mais elevada. Desse modo, o país passou a desfrutar de uma nova posição na cadeia intencional de valor, buscando nichos de mercado voltados para a exportação de produtos mais sofisticados (CANUTO; DUTZ; REIS, 2010; SOMEREN; SOMEREN-WANG, 2013; BINGWEN, 2013; DONGQI, 2013; GUANGSI, 2013; ZHAOXIA, 2013; EICHENGREEN; PARK; SHIN, 2013; OECD, 2013; LUOLIN, 2015). Em parte, essa situação explica a mudança no perfil das exportações chinesas, levando o país a diversificar sua pauta de exportações nas últimas décadas.

Figura 3: Importações e Exportações nacionais de produtos de alta tecnologia

Produtos de alta tecnologia

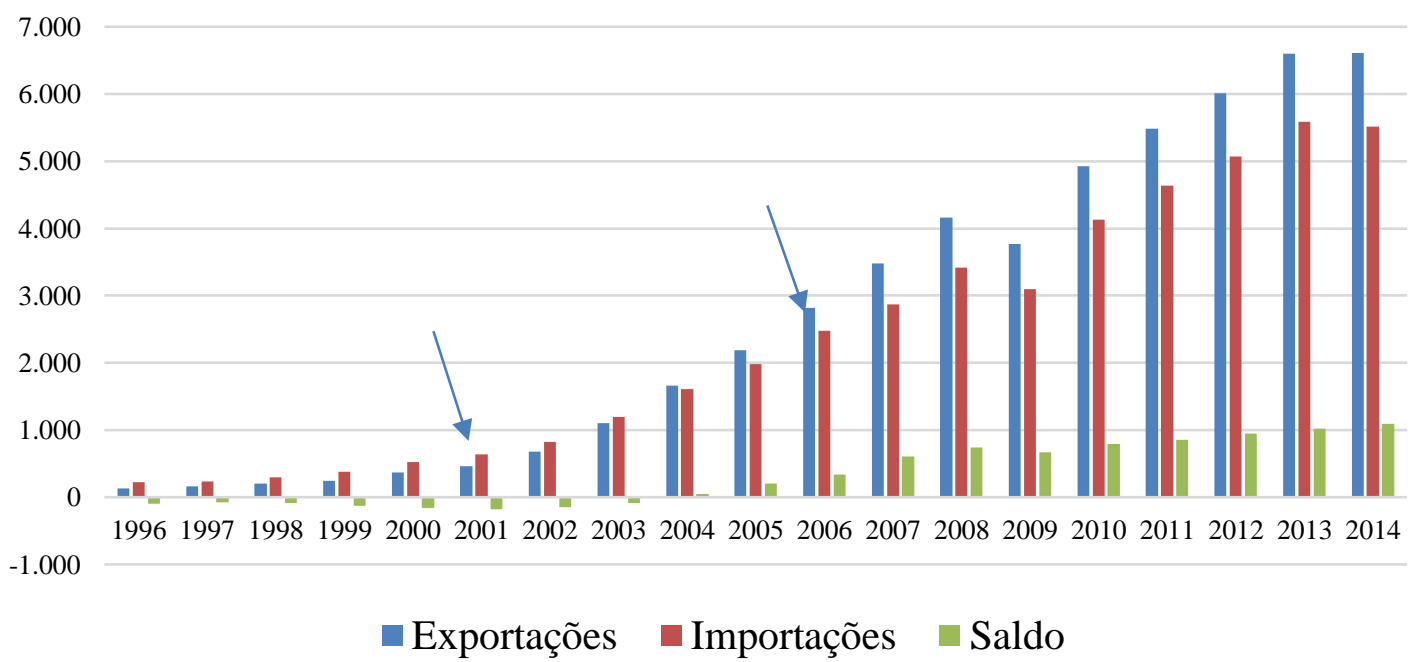

Fonte: National Bureau of Statistics (2015)

Outro ponto importante foi o forte incentivo para melhoria das condições tecnológicas da China, com o lançamento do Programa MLP (2006/2020) e com a melhoria das condições educacionais do país (UNESCO, 2013; OECD, 2016b). Com base em todas as evidências apresentadas neste estudo, é possível deduzir que esses fatores certamente contribuíram de forma positiva para a melhoria da sofisticação dos produtos exportados pelo país, porque permitiram criar condições ambientais para que os agentes nacionais pudessem absorver, decodificar e modificar as tecnologias disponíveis no exterior. As políticas públicas de $\mathrm{C}, \mathrm{T} \& \mathrm{I}$, aliadas ao aumento dos investimentos em $\mathrm{P} \& \mathrm{D}$, a melhoria das condições formais de educação e a maior articulação entre as universidades e as empresas têm demonstrado, no decorrer das últimas décadas, resultados positivos no processo de upgrade tecnológico de alguns países asiáticos (MAZZUCATO, 2013; WANG, 2013; GUANGSI, 2013; IMF, 2014; FU, 2015; DING; LI, 2015; OECD, 2016a).

No caso da China, essa situação não é diferente. Desde as reformas econômicas que foram lançadas no ano de 1978, o capital estrangeiro teve uma participação decisiva no desenvolvimento 
econômico e tecnológico da China. Inicialmente, tem-se um processo de importação de tecnologia como estratégia de qualificação técnica das atividades produtivas. Em um segundo momento, no começo dos anos 2000, observa-se o crescimento da produção de produtos de alta tecnologia, tanto das empresas domésticas quanto das multinacionais instaladas na região.

Realizada a consolidação do modelo de atração de investimentos diretos estrangeiros, proporcionada pela criação das Zonas Econômicas Especiais (ZEEs) e pela sua difusão em diversas regiões costeiras do país, a China tem tentado intensificar o processo de transferência de tecnologia. Desde o final dos anos 1990, o Estado chinês tem encorajado as multinacionais a realizar transferência de seus laboratórios de $\mathrm{P} \& \mathrm{D}$ para o país. As empresas multinacionais são atraídas por diversas vantagens oferecidas, entre as quais o gigantesco potencial do mercado chinês e o baixo custo de operação (ZHAOXIA, 2013; LUOLIN, 2015; FU, 2015; UNCTAD, 2016). Segundo dados da UNCTAD (2016), a China recebeu 136 bilhões de dólares em investimentos diretos estrangeiros no ano de 2015. Somente a região de Hong Kong recebeu a quantia de 175 bilhões de dólares. O ingresso do país na OMC permitiu que os investidores internacionais tivessem mais garantias das operações que seriam realizadas no país. Além disso, a China ainda obteve maiores opções de acesso a novos mercados no cenário internacional (PING, 2013; WORLD BANK; FU, 2015; LUOLIN, 2015; HIGGINS, 2015; FU, 2015; DING; LI, 2015; TSELICHTCHEV, 2015).

As políticas governamentais, por um bom tempo, também buscaram incentivar a importação de tecnologias e a aquisição de patentes do exterior, como fonte para melhorar os processos produtivos e realizar a engenharia reversa com inovações incrementais. Conforme observado na Figura 3, somente no ano de 2004 o saldo das exportações e importações de produtos de alta tecnologia tornou-se superavitário.

Não obstante, é importante esclarecer que as empresas de propriedade estrangeira tiveram uma parcela significativa das exportações de produtos de alta tecnologia, certa de 33\%, no ano de 2014 . Todavia, observa-se a diminuição de representatividade na parcela de exportação de produtos de alta tecnologia por parte das empresas estrangeiras (ver Tabela 1). Nos últimos anos, as firmas nacionais avançaram significativamente na parcela de exportação de produtos mais sofisticados ${ }^{16}$, e a parcela de exportações de produtos de alta tecnologia das empresas nacionais aumentou de $40 \%$, em 2008 , para 44\%, em 2014. Esse dado fortalece a ideia de que as ações do Estado na indução das inovações nativas e o crescimento das empresas nacionais tiveram efetividade. Essas informações são confirmadas por alguns estudos consultados para a elaboração deste estudo (WORLD BANK, 2013; IMF, 2014; NATIONAL BUREAU OF STATISTICS, 2015; WEF, 2016; OECD, 2016a: WIPO, 2016; IMF, 2016; UNCTADb). Outro dado que pode explicar parte desse fenômeno de aumento das exportações de produtos de alta tecnologia é o fato de as empresas nacionais terem aumentando a parcela de gastos com o $\mathrm{P} \& \mathrm{D}$, conforme é possível visualizar na Tabela 1 . Também se observa que houve aumento da parcela de exportações das empresas de propriedade compartilhada com Hong Kong, Macau e Taiwan de 17\%, em 2008, para 22\%, em 2014.

Tabela 1: Desenvolvimento de novos produtos e produção de empresas industriais (2008-2014)

\begin{tabular}{l|ccc|ccc|ccc}
\hline & \multicolumn{4}{|c|}{ Novos Produtos - unid. } & \multicolumn{2}{|c|}{$\begin{array}{c}\text { Despesas de } \\
\text { desenvolvimento de } \\
\text { novos produtos (10 000 } \\
\text { yuanes) }\end{array}$} & \multicolumn{3}{c}{$\begin{array}{c}\text { Exportações } \\
(10 \text { 000 yuanes) }\end{array}$} \\
\hline & $\mathbf{2 0 0 8}$ & $\mathbf{2 0 1 0}$ & $\mathbf{2 0 1 4}$ & $\mathbf{2 0 0 8}$ & $\mathbf{2 0 1 0}$ & $\mathbf{2 0 1 4}$ & $\mathbf{2 0 0 8}$ & $\mathbf{2 0 1 0}$ & $\mathbf{2 0 1 4}$ \\
\hline $\begin{array}{l}\text { Empresas domésticas } \\
\text { Emp. de H. K, Macau e } \\
\text { Taiwan (origem) }\end{array}$ & $74 \%$ & $72 \%$ & $79 \%$ & $69 \%$ & $70 \%$ & $75 \%$ & $40 \%$ & $42 \%$ & $44 \%$ \\
Empresas estrangeiras & $10 \%$ & $10 \%$ & $9 \%$ & $10 \%$ & $10 \%$ & $10 \%$ & $17 \%$ & $12 \%$ & $22 \%$ \\
\hline Total & $100 \%$ & $100 \%$ & $100 \%$ & $100 \%$ & $100 \%$ & $100 \%$ & $100 \%$ & $100 \%$ & $100 \%$ \\
\hline
\end{tabular}

Fonte: elaborado pelo autor com base nos dados de National Bureau of Statistics (2015).

${ }^{16}$ Conforme a classificação de Lall (2000). 
Um estudo do IMF (2016) revela que o aumento do investimento estrangeiro direto na China levou a uma transferência de tecnologia para a economia, o que, ao longo do tempo, também favoreceu o incremento das exportações de produtos manufaturados mais sofisticados. Embora as empresas multinacionais possuam uma influência substancial na exportação desses produtos, o estudo mencionado revela que a China está diminuindo gradativamente a importação de produtos considerados de média e alta tecnologia. Segundo o relatório do IMF (2016), existe uma clara diminuição do déficit de importação de produtos de média e alta tecnologia, que eram importados pela China de polos tradicionais: Japão, Taiwan e Coreia do Sul. Nesse sentido, a China está competindo com as economias mais avançadas na exportação de produtos considerados de alta tecnologia e intensivos em conhecimento ${ }^{17}$.

Outros dados que destacam o avanço das exportações chinesas de produtos relacionados a atividades de alta tecnologia são apresentados pelo relatório da UNCTAD (2013). Até o ano de 2010, as exportações relacionadas a esse segmento de produtos e serviços mais sofisticados ${ }^{18}$, em termos tecnológicos, aumentaram oito vezes quando comparadas com o ano base de 2000. Segundo a UNCTAD (2013), essa inserção recente da China, em cadeias globais de valor de produtos com maior sofisticação tecnológica, está baseada: no fluxo de investimentos diretos estrangeiros realizados no decorrer das últimas décadas; das políticas públicas executadas de absorção, difusão e disseminação do conhecimento; e na melhoria da capacidade tecnológica das empresas nacionais. A Tabela 2, a seguir, compara a participação de alguns países na cadeia global de valor em exportações por nível de sofisticação tecnológica.

Tabela 2: Exportações por nível de sofisticação tecnológica 2010

\begin{tabular}{l|c|c|c|c|c}
\hline \multicolumn{1}{c|}{ Países } & $\begin{array}{c}\text { Baseado em } \\
\text { recursos }\end{array}$ & $\begin{array}{c}\text { Baixa } \\
\text { tecnologia } \\
\text { Fabricação }\end{array}$ & $\begin{array}{c}\text { Nível médio } \\
\text { Fabricação }\end{array}$ & $\begin{array}{c}\text { Nível sofisticado } \\
\text { de Fabricação }\end{array}$ & $\begin{array}{c}\text { Serviços } \\
\text { baseados em } \\
\text { conhecimento }\end{array}$ \\
\hline África do Sul & $55 \%$ & $5 \%$ & $25 \%$ & 0 & $5 \%$ \\
Brasil & $60 \%$ & $5 \%$ & $15 \%$ & $5 \%$ & $10 \%$ \\
China & $\mathbf{1 0 \%}$ & $\mathbf{2 5 \%}$ & $\mathbf{2 0 \%}$ & $\mathbf{3 0 \%}$ & $\mathbf{5 \%}$ \\
Índia & $35 \%$ & $15 \%$ & $10 \%$ & $5 \%$ & $25 \%$ \\
Rússia & $75 \%$ & $5 \%$ & $10 \%$ & 0 & $5 \%$ \\
Malásia & $30 \%$ & $10 \%$ & $15 \%$ & $30 \%$ & $5 \%$ \\
Singapura & $20 \%$ & $5 \%$ & $15 \%$ & $35 \%$ & $15 \%$ \\
\hline
\end{tabular}

Fonte: elaborado pelo autor com base nos dados da UNCTAD (2016b) ${ }^{19}$.

Quando se examinam os dados primários fornecidos pelo portal do Banco Mundial sobre as exportações de produtos mais sofisticados em termos tecnológicos, em comparação com os Estados Unidos, é possível observar o avanço do percentual de produtos de alta tecnologia do total de exportações da China (Figura 4). No ano de 1992, os produtos exportados pela China, no segmento

17 “as exportações de economias avançadas foram inicialmente colocadas em bens de baixa tecnologia e mão-de-obra intensiva, enquanto que na parte pós-crise da amostra encontramos evidências de que a China agora está competindo em produtos de médio porte e de capital intensivo e, em menor grau, em bens de alta tecnologia e conhecimento intensivo. Vale lembrar que esta análise dos padrões de comércio não considera questões de propriedade, que são importantes para avaliar com precisão o impacto sobre os rendimentos nacionais relativos. Na verdade, o aumento da China como um exportador de produtos manufaturados tem sido levado em grande medida por empresas de propriedade estrangeira. Como resultado, embora a força de trabalho da China tenha se beneficiado da renda salarial associada à transição das empresas para a China de produção de produtores a montante em outros lugares, os retornos dos investimentos relacionados foram acumulados para investidores estrangeiros. Ainda assim, o aumento do investimento direto estrangeiro na China levou a uma transferência de tecnologia para a economia em larga escala, o que, ao longo do tempo, também permitiu que um número crescente de empresas de propriedade nacional se tornassem exportadores de produtos de fabricação neste nicho de atuação ” (IMF, 2016 p. 83, tradução nossa).

18 Conforme a classificação de Lall (2000).

${ }^{19}$ Nota: As categorias de produtos são baseadas na classificação da intensidade tecnológica disponibilizada em Lall (2000). As exportações de serviços baseadas no conhecimento incluem seguros, serviços financeiros, serviços informáticos e de informação, royalties e taxas de licenças e outros serviços empresariais. 
de alta tecnologia, representavam a parcela de 6,4\% das exportações totais do país. No mesmo ano, nos Estados Unidos, essa parcela significava 32,6\% das exportações.

No ano de 2014, do total de produtos exportados pela China, cerca de $25,40 \%$ provinha do segmento de produtos de alta tecnologia. No mesmo ano, esses números superaram as exportações estadunidenses de produtos de alta tecnologia — de 18,20\% dos produtos exportados. Vale reforçar que muitos desses produtos eram de origem japonesas e sul-coreana exportados a partir da China (FU, 2004; WORLD BANK, 2013; HIGGINS, 2015; WTO, 2016).

Figura 4: As exportações de alta tecnologia (\% das exportações de manufaturados)

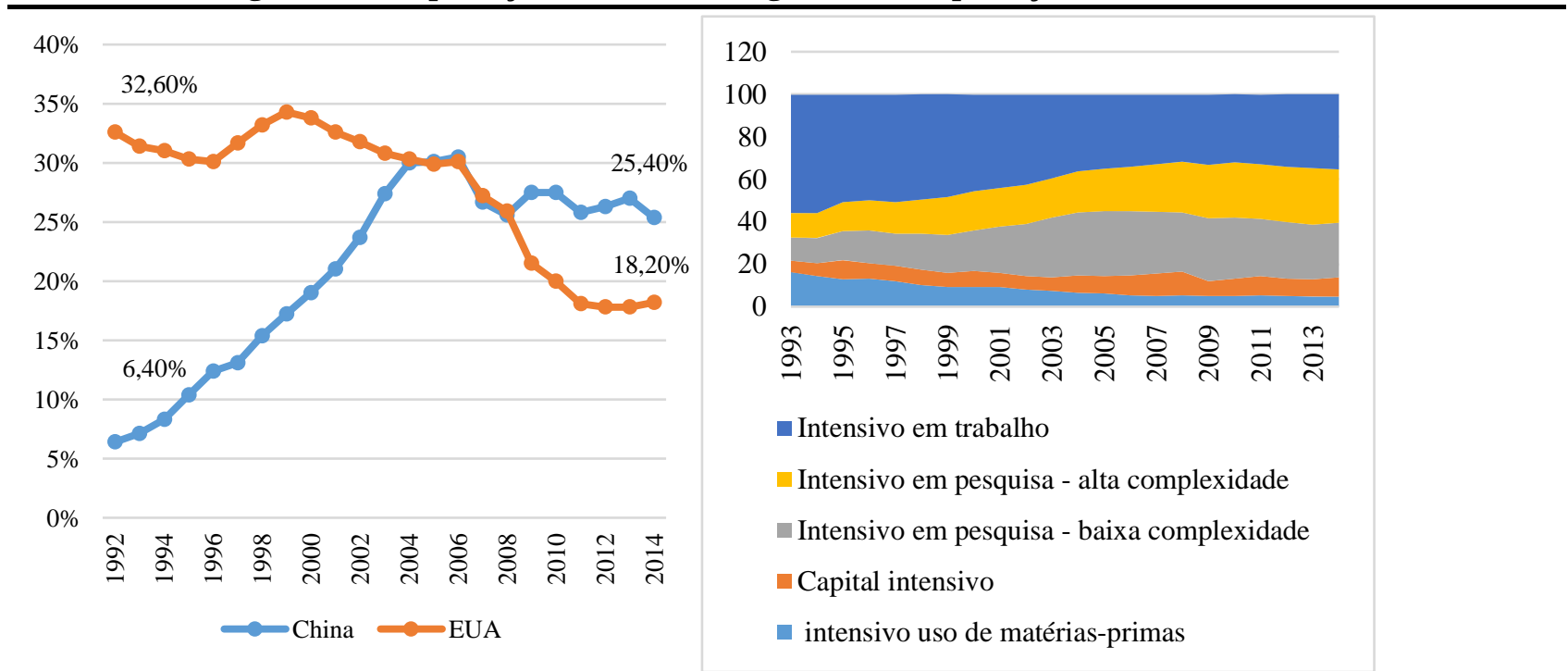

Fonte: elaborado pelo autor com base nos dados primários obtidos no portal do Banco Mundial ${ }^{20}$ (2016).

Esses dados refletem a melhora no grau de sofisticação dos produtos produzidos pela China registrados nas últimas décadas, o qual revela a melhoria das condições tecnológicas do país que passou por um processo de transformação do seu desempenho nacional de inovação. Cabe ressaltar, também, que muitas empresas estadunidenses que produziam produtos de alta tecnologia nos Estados Unidos deixaram o país em busca da possibilidade de diminuir os seus custos de produção em países da Ásia, inclusive a China (IMF, 2014 TSELICHTCHEV, 2015).

Outro dado importante que revela a diversificação e sofisticação dos produtos chineses exportados é o indicador de Índice de Qualidade de Exportação (IMF). Para o IMF (2014), a diversificação das exportações está correlacionada, de forma positiva, à transformação dos países em fase inicial de desenvolvimento econômico. Em alguns estudos recentes há evidência dos benefícios macroeconômicos da diversificação das exportações. "Existe uma forte associação das estruturas de produção mais diversificadas com menor volatilidade do produto e mais estabilidade macroeconômica" (IMF, 2014 p. 6, tradução nossa). Portanto, a diversificação e a sofisticação das exportações, fruto da maior capacidade tecnológica do país, são consideradas fatores importantes para a superação da armadilha da renda média (EICHENGREEN, 2012; LIN; TREICHEL, 2012; AGENOR; CANUTO; JELENIC, 2012; EICHENGREEN; PARK; SHIN, 2013; BINGWEN, 2013; AGENOR; CANUTO, 2014; GILL; KHARAS, 2015; OECD, 2016a, UNCTAD, 2016b). No caso do exemplo chinês, o indicador de Índice de Qualidade de Exportação (IMF) reforça os dados apresentados anteriormente. A China melhorou consideravelmente a sofisticação e a diversificação de suas exportações nos últimos anos. No começo da abertura, no final da década de 1970, o indicador estava abaixo de 0,70. Para fins de comparação, no ano de 2010 o mesmo indicador era de $0,93^{21}$.

\footnotetext{
${ }^{20}$ World Bank (2016)

${ }^{21}$ IMF (2017).
} 
Atualmente, as economias mais avançadas possuem, em média, o Índice de Qualidade de Exportação (IMF) de 0,99, e as economias em desenvolvimento 0,76.

A convergência dos dados apresentados até agora no desenvolvimento deste estudo, reforça a hipótese de que ocorreu melhoria significativa na performance nacional de geração de inovações da China. Novamente, destaca-se que o progresso tecnológico apresentado nos indicadores de inovação sugere o êxito das políticas públicas de indução das inovações nativas e da articulação dessas políticas com o setor privado do país, fornecendo um novo dinamismo ao SNI chinês. Os números positivos destacam que a estratégia de combinação das políticas de estímulo à inovação nativa, com as tecnologias disponíveis no mercado internacional, transformou, de forma positiva, a capacidade chinesa de gerar inovações. Desse modo, reforça-se a ideia de que na China existe um modelo de Sistema de Inovações que está integrado ao mercado internacional. Neste sentido, numa fase de transição, busca-se estabelecer condições internas para que as tecnologias externas sejam descodificadas e aprimoradas pelas empresas chinesas. No entanto, com base nas evidências apresentadas, o objetivo do Estado da China é estabelecer condições necessárias para que sejam viabilizadas a geração de inovações tecnológicas nativas.

Embora o país ainda possua um considerável atraso tecnológico em relação aos países considerados desenvolvidos, alguns estudos sugerem que a China já é capaz de gerar inovações incrementais baseadas no conceito de produzir bens tecnologicamente competitivos, com baixo custo e com agilidade logística. Essa combinação garante às empresas chinesas e/ou às empresas estrangeiras que estão em operação no país importantes nichos no mercado global. Mas ainda há um longo caminho para que o país atinja os objetivos estratégicos desejados em relação ao desenvolvimento tecnológico, definidos pelos Planos Quinquenais e pelos programas de ciência e tecnologia (IEDI, 2011; SOMEREN; SOMEREN-WANG, 2013; WANG, 2013; TREBAT; MEDEIROS, 2014; CHEUNG, 2014; HIGGINS, 2015; FU, 2015; DING; LI, 2015; WIPO, 2016).

\section{ANÁLISE DAS EVIDÊNCIAS DA ARMADILHA DA RENDA MÉDIA NA CHINA}

Conforme se destacou até aqui, nesta pesquisa, nas últimas décadas o Estado chinês empregou um esforço contínuo para desenvolver a capacidade tecnológica e para promover a transformação do SNI do país. Essas ações possuem o objetivo de solucionar os entraves de crescimento do país apresentados no desenvolvimento deste estudo. Para Agenor, Canuto, e Jelenic (2012) e Liu (2015) existe um receio muito grande dos governantes chineses de que o país entre na armadilha de renda média, caracterizada por uma forte desaceleração no crescimento econômico e no ritmo de produtividade pelo esgotamento dos fatores de produção. Esse fenômeno, segundo a OECD (2013), ocorre com a maioria dos países em desenvolvimento que atingiram os níveis de renda média, porém, não conseguiram atingir o nível de renda alta pelo fato de não terem superado alguns obstáculos estruturais importantes, em especial a incapacidade de gerar inovações.

Nesta seção apresentam-se as evidências pesquisadas na literatura que caracterizam os países em desenvolvimento, que entraram na armadilha da renda média. O objetivo será o de comparar essas características com os resultados dos indicadores apresentados até agora neste estudo. Para sintetizar e facilitar a análise, o Quadro 1 busca comparar as questões destacadas na literatura sobre a armadilha da renda média, com as evidências até aqui apresentadas. 
Quadro 1: Evidências da armadilha da renda média: caso da China

\section{Evidências da armadilha da renda média}

Desaceleração do crescimento

Envelhecimento da população (diminuição da força de trabalho)

Baixa diversidade na pauta de exportações

Baixa sofisticação tecnológica dos produtos produzidos no país

Rápido crescimento da renda no período anterior à desaceleração.

Indicadores de inovações internos insatisfatórios

Baixa evolução dos níveis de escolaridade

Criação de instituições voltadas para a inovação tecnológica

Aumento da desigualdade de renda

Desaceleração começou: o PIB médio per capita US\$11.000 até US\$ 15.000 (preços

constantes)

Ver: Canuto; Dutz; Reis (2010); Eichengreen (2012); Lin; Treichel (2012); Agenor; Canuto; Jelemic (2012); Eichengreen; Park; Shin (2013); Bingwen (2103); OECD (2013); Dongqi (2013); Guangsi (2013); Agenor; Canuto (2014); IMF (2014); UNESCO (2015); Fu (2015); Islam (2015); Ding;Li (2015); Gill; Kharas (2015); Lin; Treichel (2015); Liu (2015); OECD (2016a); OECD (2016b); UNCTAD (2016b); IMF (2016).

Implicações para a China (armadilha da renda média)

Recentemente a China apresentou uma leve desaceleração do crescimento

A diminuição da força de trabalho deverá ocorrer perto dos anos de 2020 e 2025 (UNESCO)

Apresentou um aumento da pauta de exportações nas últimas décadas

Aumentou o grau de sofisticação dos produtos exportados.

Nas últimas quatro décadas a China experimentou um crescimento sem precedentes.

Melhoria dos indicadores de inovações

Melhoria geral dos indicadores de educação

Nas últimas décadas ocorreu a criação de inúmeras instituições voltadas para inovação

Nas últimas décadas a China passou por um aumento da desigualdade de renda.

O PIB médio per capita ainda não superou a marca de U\$ 15.000,00 (constantes)

Ver: Agenor; Canuto; Jelenic (2012); World Bank (2013); IEDI (2011a); UNESCO (2013);

Someren; Someren-Wang (2013); Bingwen (2013); Dongqi (2013); Guangsi (2013); Zhaoxia (2013); Eichengreen; Park; Shin (2013); OECD (2013, 2016a, 2016b); IMF (2014, 2015 e 2016); Fu (2015); Ding; Li (2015); Gill; Kharas (2015); Lin; Treichel (2015); Islam (2015); Tselichtchev (2015); Liu (2015); WTO (2016); Baller; Dutta; Lanvin (2016); WIPO (2016), UNCTAD (2016 e 2016b).

Fonte: Silva (2017)

Com base em tais constatações e com as evidências apresentadas até aqui, trabalha-se com a ideia de que a China está progredindo em relação a questões importantes relacionadas à ascensão tecnológica, a fim de evitar a armadilha da renda média. Nesse caso, as evidências aqui encontradas indicam que o país pode evitar a armadilha da renda média, e que, aparentemente, não há indícios suficientes para deduzir que a pequena desaceleração econômica da China, vivenciada em um período recente, possa indicar o início de uma estagnação. Embora seja possível deduzir tal situação, é fato de que o crescimento econômico sustentável chinês está passando por um período de inúmeras provações, considerando-se os desafios apresentados nesta pesquisa e já mencionados, por exemplo, a questão energética, poluição, desigualdade de renda, envelhecimento da população e falta de recursos naturais. Para evitar a armadilha da renda média e a estagnação econômica, a China dependerá da evolução da sua capacidade de gerar inovações e do dinamismo do SNI do país.

Outro fator importante que reforça a hipótese de que a China contínua progredindo e incorporando inovações tecnológicas no processo produtivo, é a constatação de que a Produtividade 
Total dos Fatores (PTF) continua em ascensão na China. Conforme destacado na Figura 5 é possível observar que existe um crescimento constante na Produtividade Total dos Fatores no país. Conforme observa-se no gráfico, os indicadores de PTF chineses ultrapassaram os indicadores estadunidenses nos últimos anos, o que representa a manutenção e o crescimento da produtividade no país. Presumese que esse incremento é fruto das melhorias apresentadas até agora, referentes aos indicadores de inovações tecnológicas.

Os ganhos medidos pelo índice de produtividade total dos fatores, refletem a utilização mais eficiente dos insumos, está relacionado de que modo o conhecimento é empregado na produção. Neste caso, um aumento da PTF, normalmente, pode ser resultado de incorporação de inovações tecnológicas ou de melhorias técnicas no processo de produção. A melhoria da produtividade poderá resultar em níveis mais elevados de renda e qualidade de vida. As diferenças no aumento da PTF constituem a principal explicação para as disparidades no crescimento econômico (RODRIGUEZ; DAHLMAN; SALMI, 2008; AGENOR; CANUTO; JELENIC, 2012; EICHENGREEN; PARK; SHIN, 2013; IMF, 2014).

\section{Figura 5: Produtividade Total dos Fatores}

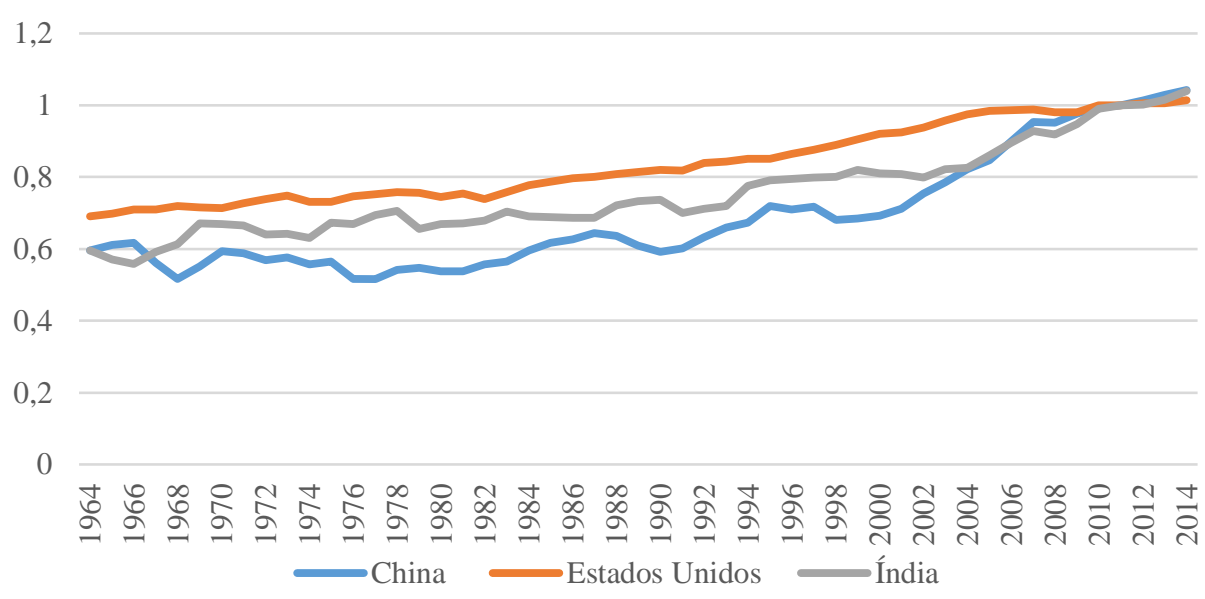

Fonte: elaborado pelo autor com base nos dados FED $^{22}(2016)$.

Por fim, apesar da melhoria destacada nos indicadores do desenvolvimento tecnológico recente da China, ainda existem muitos desafios que devem ser superados para que o país possa produzir de maneira sustentável as inovações nativas. Embora tenham ocorrido diversos avanços, destacados até aqui neste estudo, a China precisa avançar na infraestrutura de pesquisa e na mentalidade do empreendedorismo nacional. Conforme se discorreu na seção anterior, o número de pesquisadores tem se expandido de forma significativa, todavia, a qualidade, a experiência e as instituições que sustentam a pesquisa e a inovação ainda permanecem fracos por uma questão de tradição e experiência (SOMEREN; SOMEREN-WANG, 2013; PING, 2013; HIGGINS, 2015).

Para o World Bank (2013), para atingir os estágios tecnológicos desejados o governo precisa aumentar os investimentos em pesquisa básica e aplicada, além de fornecer condições para melhorar a capacidade e a qualidade dos cientistas chineses. Nesse ponto, ressalta-se a necessidade de aumentar os acordos internacionais entre universidades nacionais e do exterior para troca de experiências e rotinas de pesquisa. $\mathrm{O}$ avanço das reformas no setor de ensino superior é fundamental para a formação de pessoal qualificado, ainda mais com o cenário de envelhecimento da população do país e a diminuição da força de trabalho disponível.

${ }^{22}$ Os ganhos medidos pelo índice de produtividade total dos fatores (PTF), que refletem uma utilização mais eficiente dos insumos, têm sido reconhecidos há muito tempo como uma fonte importante de aumento de receita e de bem-estar. As diferenças nos níveis de renda e nos índices de desenvolvimento em diferentes países são em grande parte devidas às diferenças na produtividade (AGENOR; CANUTO; JELENIC, 2012; EICHENGREEN; PARK; SHIN, 2013; IMF, 2014). 
Por sua vez, as políticas voltadas ao desenvolvimento dos sistemas de inovação (nacional, regional e local) são fundamentais para que a China continue avançando no processo de transformação tecnológica. As políticas públicas devem avançar ainda mais na difusão do conhecimento para que todas as regiões da China possam ter a capacidade de desenvolver tecnologias e usufruir dos benefícios e oportunidades gerados pela melhoria do progresso técnico. A interação entre as políticas públicas de fomento a inovação e as ações individuais das empresas devem seguir progredindo para que a sinergia entres os agentes do SNI possa representar ganhos sociais desejáveis para a nação.

\section{CONCLUSÕES DO ESTUDO}

A partir das evidências apresentadas, mesmo que os modelos de desenvolvimento tecnológico dos países asiáticos possuam características e momentos históricos diferentes, considera-se que a China poderá seguir o mesmo caminho de países como Coreia do Sul e Taiwan, que superaram com sucesso a armadilha da renda média, tornando-se países de renda alta e com alta capacidade de gerar inovações. Todavia, a trajetória chinesa para atingir este status ainda é bastante incerta devido à magnitude das restrições apresentadas e a urgência de algumas medidas relacionadas com as questões ambientais e de distribuição de renda.

No contexto observado na China, o modelo de atração de multinacionais, com o objetivo de compartilhar conhecimentos, mostrou-se insuficiente para os novos desafios que foram gerados pelo êxito do próprio crescimento chinês a partir de meados dos anos 2000. Para que o país supere o patamar da renda média e se torne uma nação de renda elevada, evitando a armadilha da renda média, a geração de riqueza e a distribuição de renda devem permanecer em uma trajetória de crescimento na China. Logo, esse cenário só será possível se a produtividade e a acumulação de capital continuar na trajetória ascendente, mas com bases solidas de desenvolvimento. Nessa realidade, as inovações são fundamentais para que o país consiga se especializar nos ramos mais intensivos em conhecimentos (nanotecnologia, biotecnologia, energias renováveis, tecnologia aeroespacial, ciências médicas e tecnologia da informação). Esses ramos possuem como característica a dificuldade de imitação e a possibilidade de promover grandes surtos de inovações (destruição criativa) por diversos setores da economia. Além disso, esses ramos podem fornecer ganhos de produtividade para outros setores correlatos.

Contemplando todas as novas exigências que foram apresentadas em decorrência do crescimento econômico da China, o Programa MLP (2006/2020) foi formulado para combater os problemas críticos do desenvolvimento científico e tecnológico do país. O projeto teve o objetivo de promover a inovação nativa (Zizhu Chuangxin), além de impulsionar as forças produtivas da China para a criação de tecnologias em áreas consideradas estratégicas. Devido à criação do programa e de sua articulação com as metas estabelecidas pelos últimos Planos Quinquenais, o ano de 2006 marcou o ponto de transformação das políticas de fomento a inovação. A partir desse período a China passou a denominar-se uma potência que buscava desenvolver a capacidade de gerar inovações nativas como forma de solucionar problemas locais de desenvolvimento.

É indiscutível que ocorreram avanços significativos nas últimas décadas na China. Os indicadores aqui apresentados corroboram com os dados apresentados por outros estudos sobre o tema. O resultado dessa transformação é atribuído à forte interação entre setor público e privado do país. Cabe ressaltar, mais uma vez, o papel decisivo dos projetos do Estado para facilitar o processo de transferência tecnológica para a China e para promover a melhoria das condições internas de inovação. As evidências empíricas apresentadas neste trabalho, sugerem que a China está criando as condições necessárias para superar os obstáculos e fomentar estratégias exitosas, que permitam a transição do país do status de renda média para alta nas próximas décadas. Portanto, rejeita-se, até o momento a ideia de que o país esteja entrando em um período de estagnação oriundo do processo descrito na literatura como armadilha da renda média. 


\section{REFERÊNCIAS}

AGÉNOR, Pierre-Richard; CANUTO, O; e JELENIC, Michael. Avoiding Middle-Income Growth Traps. Washington DC: WORLD BANK, Poverty Reduction and Economic Management (Prem) Network, Nov. 2012.

AGENOR, Pierre-Richard; CANUTO, Otaviano. Access to Finance, Product Innovation and Middle-Income Traps. Washington DC: Policy Research Working Paper 6767, World Bank, 2014.

BALLER, Silja; DUTTA, Soumitra; LANVIN, Bruno. The Global Information Technology Report 2016. Geneva: World Economic Forum, 2016.

BINGWEN, Zheng. A "armadilha da renda média" e as quatro fases do crescimento econômico da China. In: PEREIRA, Lia V., VELOSO, Fernando, BINGWEN, Zheng. Armadilha da renda média: visões do Brasil e da China. Vol.2. Rio de Janeiro: Editora FGV, 2013, p. 19-54

CANUTO, O e GIUGALE, Marcelo (eds). The day after tomorrow: a handbook on the future of economic policy in the developing world. Washington DC: WORLD BANK, 2010.

CHANG, Ha-Joon. Um estudo sobre a relação entre Instituições e Desenvolvimento Econômico - algumas questões teóricas fundamentais. Oikos, n. 10, ano VII, $2008 \mathrm{~b}$.

CHEUNG, Tai Ming. Frameworks for Analyzing Chinese Defense and Military Innovation. In: ( org.). Forging China's Military Might: A New Framework for Assessing Innovation.

Baltimore: Johns Hopkins, 2014. P. 15 - 46.

DING, Xuedong; LI, Jun. Incentives for Innovation in China: Building an innovative economy. New York: Routledge, 2015.

DONGQI, Chen. Os determinantes do crescimento econômico chinês. PEREIRA, Lia V., VELOSO, Fernando, BINGWEN, Zheng. Armadilha da renda média: visões do Brasil e da China. Vol.2. Rio de Janeiro: Editora FGV, 2013, p. 55-86.

EICHENGREEN, Barry. "Escaping the Middle Income Trap," in Federal Reserve Bank of Kansas City, Achieving Maximum Long Run Growth, 2012. Disponível em:

$<$ https://www.kansascityfed.org/publicat/sympos/2011/Eichengreen_final.pdf >. Acesso em: 01 Fev. 2016.

EICHENGREEN, Barry; PARK, Donghyun; SHIN, Kwanho. Growth slowdowns redux: Avoiding the middle-income trap. CEPR's Policy Portal, Research-based policy analysis and commentary from leading economists, 11 Jan. 2013. Disponível em: <http://voxeu.org/article/growthslowdowns-redux-avoiding-middle-income-trap> > . Acesso em: 01 Fev. 2016.

FEDERAL RESERVE BANK OF ST. LOUIS - FED. Economic Data: Total Factor Productivity at Constant National Prices for China. St. Louis, EUA. Disponível em: <

https://fred.stlouisfed.org/series/RTFPNACNA632NRUG >. Acesso em: 01.2016.

FU, Xiaolan. China's Path to Innovation. Cambridge, Reino Unido: Cambridge University Press, 2015.

FREEMAN, Chris; SOETE, Luc. A Economia da Inovação Industrial. Campinas, SP: Editora da Unicamp, 2008.

GILL, Indermit S. e KHARAS, Homi. The Middle-Income Trap Turns Ten. Singapore: Policy Research Working Paper, World Bank, Aug. 2015.

GUANGSI, Li. Inovação tecnológica na China. In: PEREIRA, Lia V., VELOSO, Fernando, BINGWEN, Zheng. Armadilha da renda média: visões do Brasil e da China Vol.2. Rio de Janeiro: Editora FGV, p.87-114, 2013. 
HIGGINS, Victoria. Alliance Capitalism, Innovation and the Chinese State: The Global Wireless Sector. London: Palgrave Macmillan, International political economy series, 2015.

HODGSON, Geoffrey M. What Are Institutions? Journal of Economic Issues. Vol. XL No. 1 Mar. 2006.

INSTITUTO DE ESTUDOS PARA O DESENVOLVIMENTO INDUSTRIAL - IEDI - FREITAS, Maria C. PENIDO de. A Transformação da China em Economia Orientada à Inovação. São Paulo, IEDI - Instituto de Estudos para o Desenvolvimento Industrial, 2011.

INTERNATIONAL MONETARY FUND - IMF. Sustaining Long-Run Growth and Macroeconomic Stability in Low-Income Countries-The Role of Structural Transformation and Diversification. Washington, D.C.: International Monetary Fund, 2014.

. Asia and Pacific: Building on Asia's Strengths during Turbulent Times. Washington,

D.C.: International Monetary Fund, 2016.

ISLAM. S. Nazrul. Will Inequality Lead China to the Middle Income Trap? Department of Economic \& Social Affairs. DESA Working Paper. No. 142 ST/ESA/2015/DWP/142, 2015.

KISSINGER, Henry. Sobre a China. Rio de Janeiro: Editora Objetiva, 2011

LALL, S. "The Technological Structure of Performance of Developing Country Manufactured Exports, 1985- 1998”, QEH Working Paper Series, No.44, 2000.

LIN, Justin Yif; TREICHEL, Volker. Learning from China's Rise to Escape the Middle-Income Trap: A New Structural Economics Approach to Latin America. Washington DC: Policy Research Working Paper 6767, World Bank, 2012.

LUOLIN, Wang. China's WTO Accession Reassessed. New York: Routledge Taylor \& Francis Group, 2015.

MAZZUCATO, Mariana. The Entrepreneurial State: Debunking Public vs. Private Sector Myths. London, Anthem Pres, 2013.

MEDEIROS, Carlos Aguiar. Padrões de investimento, mudança institucional e transformação estrutural na economia chinesa. In: BIELSCHOWSKY, Ricardo (Org.). Padrões de desenvolvimento econômico (1950-2008): América Latina, Ásia e Rússia. - Brasília: Centro de Gestão e Estudos Estratégicos, 2013. v.1; v.2; total 924 p.435-489.

METCALFE, Stan. Institutions and Progress. The University of Manchester \& UMIST, CRIC Discussion Paper No 45 jun. 2001.

NATIONAL BUREAU OF STATISTICS - NBS, 2015. China Statistical Yearbook 2010, Beijing: China Statistics Press. Disponível em: < http://www.stats.gov.cn/tjsj/ndsj/2014/indexeh.htm >. Acesso em: 01 Ago. 2016.

THE ORGANIZATION FOR ECONOMIC CO-OPERATION AND DEVELOPMENT - OECD. Reviews of Innovation Policy: China. China science and technology report, 2008.

Avoiding the Middle-Income Trap: Policies For Sustained And Inclusive Growth. The People's Republic of China, September 2013.

. G20 INNOVATION REPORT 2016. Beijing, China, 4 november 2016a. Disponível em: <https://www.oecd.org/china/G20-innovation-report-2016.pdf> Acesso em: 1 Ago. 2016.

PEREZ, Carlota. Revoluciones Tecnológicas y Capital Financiero: La dinámica de las burbujas financieras y las épocas de bonanza. México: Siglo XXI, 2004.

PING, LV. China. In: SCERRI, Mario; LASTRES, Helena (Org.) BRICS - National Systems of Innovation: The Role of the State. New Delhi, Routledge, 2013, p. 188-247. 
RODRIGUEZ, Alberto; DAHLMAN, Carl; SALMI, Jamil; Knowledge and innovation for competitiveness in Brazil. Washington, DC: The International Bank for Reconstruction and Development; World Bank, 2008

SCHUMPETER, Joseph A. Capitalismo, Socialismo e Democracia. Rio de Janeiro: Zahar, [1942] 1984.

SILVA, Ricardo M. Muccillo. O sistema nacional de inovação da China em transição: a dinâmica de atuação do estado na indução das inovações nativas - Zizhu Chuangxin. Tese (Doutorado em Economia) - Faculdade de Ciências Econômicas, Universidade Federal do Rio Grande do Sul. Porto Alegre, p. 274. 2017.

SOMEREN, Taco C.R. Van; SOMEREN-WANG, Shuhua Van. Innovative China: Innovation Race Between East and West. Canada: Editora Springer, 2013.

TSELICHTCHEV, Ivan. China versus Ocidente: o deslocamento do poder global no século XXI. São Paulo: DVS editora, 2015.

TREBAT, Nicholas M.; de MEDEIROS, Carlos A. Military Modernization in Chinese Technical Progress and Industrial Innovation. Review of Political Economy, v. 26, p. 303-324, 2014.

UNITED NATIONS EDUCATIONAL, SCIENTIFIC AND CULTURAL ORGANIZATION UNESCO. Science Report: Towards 2030. Paris: Published in 2015 by the United Nations Educational, 2015.

UNITED NATIONS EDUCATIONAL, SCIENTIFIC AND CULTURAL ORGANIZATION UNCTAD. The World Investment Report 2016. Investor Nationality: Policy Challenges. Geneva: UNITED NATIONS PUBLICATION, 2016a. Disponível em:

<http://unctad.org/en/PublicationsLibrary/wir2016_en.pdf>. Acesso em: 01 ago. 2016.

. Trade and Development Report, 2016. Geneva: UNITED NATIONS PUBLICATION, 2016b. Disponível em: <http://unctad.org/en/PublicationsLibrary/tdr2016_en.pdf >. Acesso em: 01 ago. 2016.

China: education system. Quebec, 2016. Disponível em:

<http://uis.unesco.org/country/cn>. Acesso em 01 ago. 2016.

UNITED NATIONS DEVELOPMENT PROGRAMME - UNDP \& DRC. China National Human Development Report 2016: Social Innovation for Inclusive Human Development. Beijing: This report is a collaboration between UNDP China and Development Research Center of the State Council of China, 2016.

WANG, Cassandra. Upgrading China's Information and Communication Technology Industry. USA, World Scientific, 2013.

WEBER, Max. Economia e sociedade; fundamentos da sociologia compreensiva. 4.ed. Brasília: Ed. Universidade de Brasília, volume 1, 2012.

WORLD INTELLECTUAL PROPERTY ORGANIZATION - WIPO. The Global Innovation Index 2016: Winning with Global Innovation. University, INSEAD, and the World Intellectual Property Organization (WIPO), 2016.

WORLD BANK. China 2030: Building a Modern, Harmonious, and Creative Society. Washington DC, 2013.

WORLD TRADE ORGANIZATION - WTO. Trade Policy Review: Report By China. World Trade Organization, 15 June 2016.

ZHAOXIA, Hu. Comércio exterior e investimento direto estrangeiro da China. In: PEREIRA, Lia V., VELOSO, Fernando, BINGWEN, Zheng. Armadilha da renda média: visões do Brasil e da China Vol.2. Rio de Janeiro: Editora FGV, 2013, p. 205-238. 